\title{
Copeptin in heart failure
}

This article was published in the following Dove Press journal:

Research Reports in Clinical Cardiology

I July 2014

Number of times this article has been viewed

Bartosz Lasota'

Katarzyna Mizia-Stec ${ }^{2}$

'2nd Department of Cardiology, Medical University of Silesia,

Katowice, Poland;

${ }^{2}$ Ist Department of Cardiology,

Medical University of Silesia,

Katowice, Poland
Correspondence: Bartosz Lasota Medical University of Silesia, 2nd Department of Cardiology, Ziolowa 45/47; 40-635 Katowice, Poland

Tel +48 323598694

Fax +48 323598694

Email blasota@poczta.onet.pl
Abstract: Copeptin is a novel indicator of arginine-vasopressin activation in the body. Its value has primarily been documented in acute life-threatening conditions mediated by the stress response system. Recently, some studies have revealed copeptin's promising role as a marker in cardiovascular diseases. In our review, we summarize the current knowledge on copeptin in pathophysiology, as well as in risk assessment in different clinical settings involving the cardiovascular system with a special focus on heart failure.

Keywords: copeptin, heart failure, arginine-vasopressin

\section{Introduction}

Heart failure (HF) is a clinical syndrome resulting from improper cardiac morphology or function that leads to impaired oxygen transport in the body in relation to demand. Symptoms such as dyspnea, fatigue, and peripheral edema are not specific and have limited diagnostic value. ${ }^{1,2}$ Myocardial diseases are the most common causes of HF that lead to left ventricular systolic/diastolic dysfunction; other causes include valvular heart disease, endocarditis, arrhythmias, and conduction abnormalities. Recognition of the correct causes of HF is the basis for determining accurate treatment, which can lead to an improved prognosis for patients.

HF occurs in $1 \%-2 \%$ of the adult population in developed countries, and this rate rises to more than $10 \%$ in those $\geq 70$ years. $^{3}$ In recent years, effective therapies have improved patient outcomes, and they have contributed to a relative reduction in the number of hospitalizations by $30 \%-50 \%$; in addition, a smaller but significant decrease in the number of deaths due to HF have also been observed. ${ }^{4-6}$

Due to the noncharacteristic signs and symptoms of HF, echocardiography is ordered for many patients with suspected HF. Additionally, novel biochemical markers of the diagnosis and prognosis of HF, which have been approved by the European Society of Cardiology, are the natriuretic peptides, brain natriuretic peptide (BNP) and N-terminal prohormone brain natriuretic peptide (NT-proBNP). ${ }^{7}$ Copeptin is a relatively new and promising marker of various cardiovascular events, including $\mathrm{HF}$, as it an indicator of the activity of the vasopressin system.

\section{Synthesis and release of copeptin}

The arginine-vasopressin (AVP) complex, which is sometimes called an antidiuretic hormone, plays a crucial role in maintaining the homeostasis of the cardiovascular system. The importance of AVP in clinical practice is limited because of its ex vivo 
instability, small size, interactions with platelets in the serum, and short plasma half-life (24 minutes in vivo). ${ }^{8}$

Copeptin was described for the first time by Holwerda in $1972 .{ }^{9}$ In a sense, the finding of the glycopeptide was surprising. Never before had a glycoproteide of such relatively low molecular mass been isolated from tissue (an extract from the posterior lobes of pig pituitaries contained a glycopeptide with a molecular mass of about 3,200). ${ }^{9}$ Copeptin is a 39 -amino acid protein with a core of leucine. A precursor for AVP and copeptin is pre-provasopressin, which consists of 164 amino acids, including a signal peptide, AVP, copeptin, and neurophysin II. Copeptin is, therefore, a C-terminal fragment of pro-AVP, which is secreted in response to the same factors that AVP responds to (hypovolemia, hyponatremia, an increase in osmolality, pain, stress, hypoxia, hypercapnia, and acidosis), but it is solid at room temperature and easy to isolate and determine. ${ }^{10}$ The secretion of AVP/copeptin is stimulated by baroreceptor/ osmoreceptor stimulation, which is involved in the regulation of blood volume, blood pressure, endotoxins, and the cytokines (including interleukin-1 $\beta$, interleukin-6, and tumor necrosis factor- $\alpha$ ). ${ }^{1-13}$ Copeptin is released together with AVP in stoichiometric concentrations, reflecting an individual's stress level. ${ }^{14}$

The synthesis process is primarily carried out due to an endocrine mechanism within the hypothalamic nuclei (the paraventricular and supraoptic in magnocellular neurons;Figure 1). Pro-AVP gets to the posterior part of the gland through the infundibulum of the pituitary gland. The mature AVP is released in a further step involving enzymatic transformations with the help of copeptin and neurophysin II. Secretion from the neurohypophysis takes place in response to osmotic and hemodynamic changes (pressure drop). ${ }^{15}$ Another synthetic route passes through the parvocellular neurons - the so-called hormone-producing neurons in the hypothalamus, where it is synthesized into a corticotropinreleasing hormone, among others. In this case, AVP directly affects the endocrine cells of the pituitary gland via the portal circulation. The release of adrenocorticotropin (ACTH) and cortisol in response to stressful stimulation shows a significant synergism between corticotrophin-releasing hormone and AVP, which confirms the stress element as a factor in triggering the production of AVP, which then stimulates the release of $\mathrm{ACTH} .{ }^{15-17}$
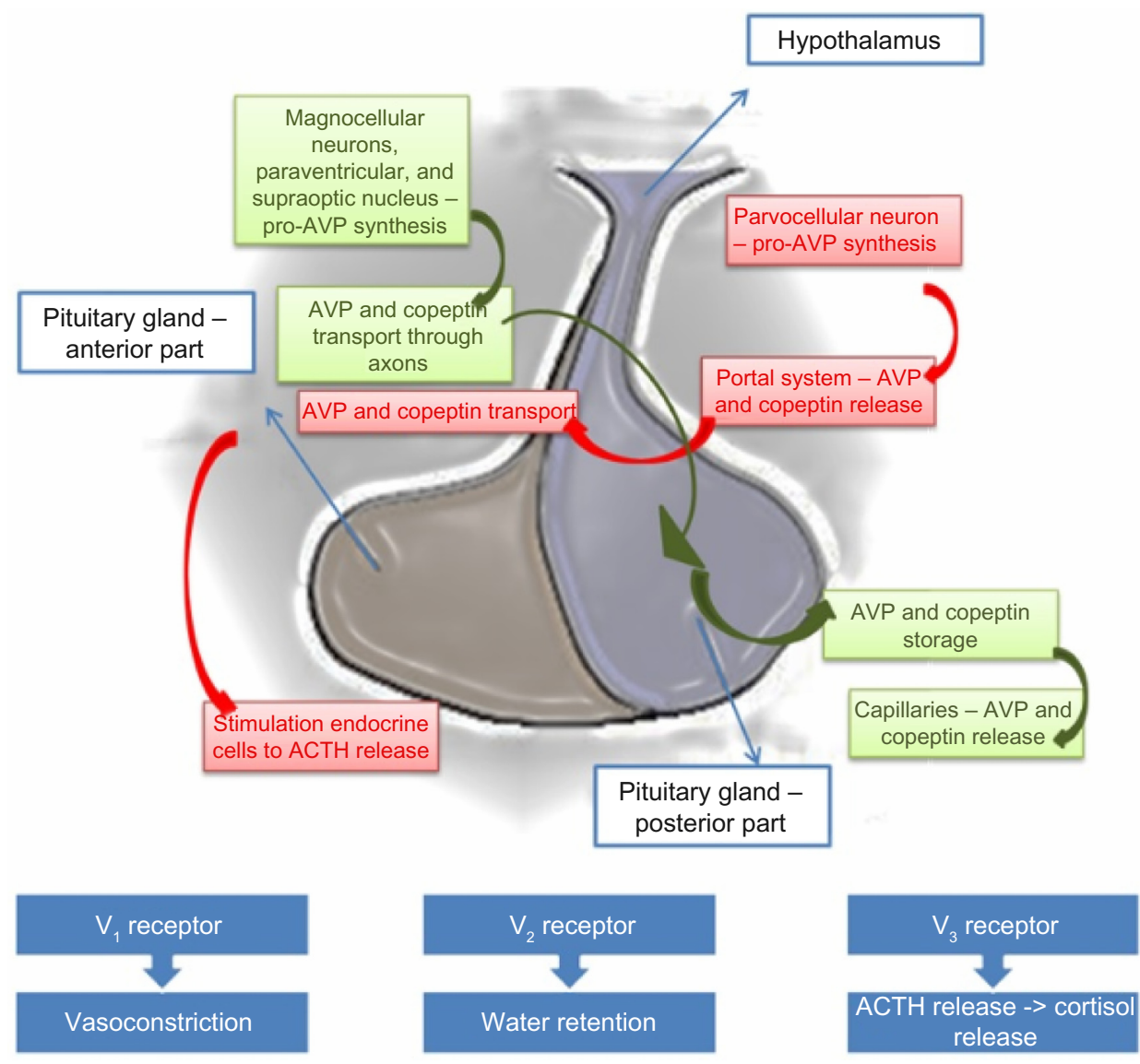

Figure I Pathogenesis of the synthesis and release of copeptin.

Abbreviations: AVP, arginine-vasopressin complex; ACTH, adrenocorticotropin. 
AVP acts on the three types of receptors: $V_{1}$, which is responsible for vasoconstriction; $\mathrm{V}_{2}$, which has an antidiuretic effect; and $\mathrm{V}_{3}$, which is involved in the release of ACTH. ${ }^{15} \mathrm{~V}_{1}$ receptors are most often located within the arterial smooth muscle and induce vasoconstriction through the intracellular influx of calcium ions through the G-protein. ${ }^{15} \mathrm{~V}_{1}$ receptors are also situated in the cardiac muscle cells, but their effectiveness has not been clarified..$^{18} \mathrm{~V}_{2}$ receptors within the renal tubules, by increasing intracellular cyclic adenosine monophosphate, exert a dual effect on water: they contribute to an increase in the synthesis of messenger ribonucleic acid encoding aquaporin 2, a protein that forms the membrane channels; and they are involved in the transport of that protein to the renal collecting duct that allows water to be reabsorbed from urine. ${ }^{15} \mathrm{AVP}$ is also related to oxytocin receptors in the endothelial cells, and induces vasodilatation that is dependent on nitric oxide and certain purinergic receptors. ${ }^{19}$ Following activation by AVP, receptors for oxytocin in the heart can lead to an increased release of atrial natriuretic peptides, while activation of purinergic $P_{2}$ receptors can have a negative inotropic effect that can cause coronary vasospasm. ${ }^{20,21}$

In healthy subjects, the mean concentration of copeptin is $<5 \mathrm{pmol} / \mathrm{L} .^{22}$ Men demonstrate higher concentrations of copeptin (although not significant), as do individuals with hyponatremia and dehydration. ${ }^{22}$ Age has no significant effect on the identification of copeptin. ${ }^{10,15}$ Lower copeptin concentrations are observed in individuals with diabetes insipidus and hypervolemia. ${ }^{23}$

The method used to determine copeptin, as described by Morgenthaler et al in 2006, ${ }^{10}$ was based on using two polyclonal antibodies directed against the 132-164 amino acid sequence C-terminal part of pre-provasopressin. The high sensitivity of this method $(1.7 \mathrm{pmol} / \mathrm{L})$ allowed for a reduction in the volume of the plasma samples to $50 \mu \mathrm{L}$, reducing iatrogenic blood loss. Determination is characterized by high stability in the plasma or serum ex vivo which is, therefore, evident by a loss of less than $20 \%$ of the blood samples stored for 7 days at room temperature and 14 days at $4^{\circ} \mathrm{C}$ after downloading the ethylenediaminetetraacetic acid. ${ }^{10}$ Presently, the determination of copeptin is based on enzymelinked immunosorbent assay. Available tests have high sensitivity and excellent specificity for the detection of copeptin and, moreover, no significant cross-reactivity or interference between copeptin and the analogs was observed. ${ }^{24}$

\section{Copeptin in cardiovascular and kidney diseases}

Copeptin has come to be regarded as an important marker used to identify patients who are at high risk for various diseases, and it is also used as a performance predictor in these diseases. ${ }^{14}$ It improves the clinical value of the biomarkers and tools that have previously been used for evaluating risk stratification. An increased activation of AVP and higher copeptin concentrations have been described in different acute disorders. ${ }^{14}$ However, the main area of development for copeptin and the importance of copeptin measurement are emphasized in the cardiovascular system. Important data are observed in the case of coronary artery disease for both stable angina and acute coronary syndromes. A determination of the copeptin level, which is often compared to the cardiac necrosis enzymes such as troponin I or T, allows for the faster differential diagnosis of pain in the chest, better risk stratification, and for the prediction of adverse cardiovascular events and prognosis. ${ }^{25-30}$ The copeptin concentration in the blood serum was also higher in patients with symptomatic mitral stenosis, which regresses after percutaneous balloon mitral valve plasty, which is observed along with a reduction in the transmitral pressure gradient and systolic pulmonary artery pressure. ${ }^{31}$ The importance of copeptin was documented in severe aortic stenosis, with preserved left ventricular systolic function regardless of the copresence of coronary artery disease. ${ }^{32}$ The importance of AVP has also been described in cardiovascular shock states. ${ }^{15,33,34}$

It should be noted that the significance of the role of the concentration of copeptin has also been observed in other diseases that worsen the prognosis of cardiovascular events, namely: chronic obstructive pulmonary disease $;^{35}$ diabetes insipidus $;{ }^{36}$ respiratory infections, including pneumonia; ${ }^{37}$ septic shock and hemorrhagic shock; $;^{38}$ ischemic stroke; ${ }^{39}$ intracerebral hemorrhage, ${ }^{40}$ and the prediction of mortality after injury of the central nervous system. ${ }^{41}$

Copeptin concentration is also an important marker of the progression of renal dysfunction, as measured by the glomerular filtration rate (GFR) index. ${ }^{42,43}$ Electrolyte disturbances are common in cardiovascular (especially HF) and renal diseases, including the most commonly seen hyponatremia. Copeptin is valuable in the diagnostic work-up of hyponatremic conditions. Li et a ${ }^{44}$ revealed that BNP and copeptin appear to provide sensitive biological markers for the evaluation of atherosclerosis in patients with chronic kidney disease; BNP and copeptin levels were significantly higher in the chronic kidney disease group than in the control group. Both indices increased progressively, in parallel with the decline in GFR. Velho et $\mathrm{al}{ }^{45}$ showed that plasma copeptin concentrations may help to identify subjects with diabetic chronic kidney disease who are at high risk for renal function decline. Moreover Fenske et $\mathrm{al}^{42}$ showed that copeptin levels are strongly associated with stroke, sudden death, combined 
cardiovascular events, and mortality in hemodialysis patients with type 2 diabetes. Surprisingly, Bosselmann et $\mathrm{al}^{46}$ showed that copeptin is closely associated with renal function in $\mathrm{HF}$; however, its prognostic significance is not affected by renal disease, and copeptin can be used for risk stratification, independent of renal function.

\section{AVP and heart failure}

The importance and role of AVP in chronic HF are well known and documented. ${ }^{15}$ AVP, which affects the $\mathrm{V}_{1}$ and $\mathrm{V}_{2}$ receptors, promotes conversion and left ventricular dysfunction, hypertrophy, and cardiac remodeling. The progression of adverse remodeling is promoted by other activities of AVP: the stimulation of protein and cardiac fibroblast synthesis; an increased afterload; and vascular/heart wall tension. ${ }^{47-49}$ The prognostic value of AVP in HF has also been described. ${ }^{15}$ In patients with systolic dysfunction and a left ventricular ejection fraction (LVEF) $\leq 40 \%$ after myocardial infarction, increased concentrations of AVP have been associated with a worse prognosis - a greater risk of cardiovascular mortality, the development of acute HF, and subsequent episodes of myocardial infarction. ${ }^{15}$ As copeptin reflects AVP system activity, several reports have also shown the importance of copeptin in HF. These were related to diagnosis, symptomatology, and prognosis, and they are described below.

\section{Copeptin and the prognosis of heart failure}

The largest amount of available data concerns the prognostic role of copeptin. Much of the data is associated with postinfarction left ventricular systolic dysfunction. Many compare the importance of copeptin with a well-known marker of HF - natriuretic peptides. An evaluation of the patient's prognosis plays an especially crucial role in those who are qualified to be treated with implantable devices or other cardiac surgery (including heart transplantation), as well as in the care planning in the end-of-life period of patients.

Patients with high concentrations of copeptin had a significantly worse prognosis compared to those with lower concentrations of copeptin. ${ }^{50-53}$ Stoiser et $\mathrm{al}^{50}$ showed that copeptin was an excellent prognostic indicator in advanced HF. Its value was greater than BNP in the prediction of death or death and rehospitalization taken together, while BNP was still suitable for the prediction of chronic HF and rehospitalization. Gegenhuber et $\mathrm{al}^{51}$ evaluated the prognostic value of copeptin in acute decompensated HF. Similar to BNP, concentrations of copeptin were characterized by their significant prognostic value in the assessed annual mortality, regardless of the cause. ${ }^{51}$ In the LAMP Study (Leicester Acute Myocardial Infarction Peptide), Khan et $\mathrm{al}^{54}$ evaluated the prognostic significance of copeptin in patients after myocardial infarction in the context of HF. Plasma copeptin concentrations were highest on admission ( $P<0.001$; day 1 versus days $2-5)$ and reached a plateau on days 3-5. Copeptin concentrations were significantly higher in patients who died or were re-hospitalized with symptoms of HF (median $18.5 \mathrm{pmol} / \mathrm{L}$ versus $6.5 \mathrm{pmol} / \mathrm{L} ; P<0.0005$ ). Copeptin was also an independent predictor of death or HF within 60 days, and its concentration was significantly related to the degree of left ventricular remodeling. ${ }^{54,55}$ It was shown that copeptin concentrations above $7 \mathrm{pmol} / \mathrm{L}$, particularly when coexisting with NT-proBNP $>900 \mathrm{pmol} / \mathrm{L}$, were considered significantly prognostic. ${ }^{54}$ In the OPTIMAAL Study (the Optimal Therapy in Myocardial Infarction with the Angiotensin II Antagonist Losartan), Voors et al ${ }^{56}$ confirmed the aforementioned reports of Khan et al, ${ }^{54}$ and demonstrated that copeptin was an independent predictor of mortality and morbidity in patients with HF after myocardial infarction, and it could have a stronger predictive value compared to the concentrations of BNP and NT-proBNP.

The prognostic role of serial measurements of emerging neurohormones, such as copeptin, in a group of chronic HF patients undergoing increased HF-specific therapy was also assessed. ${ }^{57}$ Copeptin concentrations were evaluated in a group of patients with chronic HF after an incident of exacerbation. Medication treatment was gradually increased until optimized, and copeptin concentrations were observed before and after the optimization of therapy. Angiotensin-converting enzyme/angiotensin receptor blockers and $\beta$-blockers were increased significantly during the 3 -month titration period ( $P<0.0001$ for both). Baseline and follow-up copeptin concentrations were predictors of the primary endpoint (all-cause mortality at 24 months) (baseline hazard ratio [HR]: 1.92; 95\% confidence interval [CI]: $1.233-3.007 ; P=0.004)$.

Ambiguous data on the prognostic significance of copeptin was derived from the large GISSI-HF study (Gruppo Italiano di Studio della. Sopravvivenza nella Insufficienza cardiaca-Heart Failure). ${ }^{58}$ This study was performed on 1,237 patients with chronic and stable HF. The aim was to assess the predictive value of stable precursor fragments of different vasoactive peptides - among them, copeptin. Baseline concentrations were independent predictors of the clinical outcome at the median follow-up of 3.9 years. However, all markers, with the exception of copeptin, had prognostic accuracy, as measured with the $c$-statistic, which was 
similar to that of the BNPs, and remain the best biomarkers in chronic HF.

Since copeptin is involved in water and electrolyte management, the influence of plasma sodium on the prognostic significance of copeptin concentrations in HF patients was also evaluated. ${ }^{59}$ In cases of acute HF, the dose of the diuretics that were used reached their maximum. Copeptin was a significant predictor of hospitalization or death $(P<0.019)$, but they did not predict mortality independently from NT-proBNP. Copeptin concentrations also did not predict the future development of hyponatremia. In addition, copeptin was a predictor of mortality in HF, regardless of the serum sodium concentrations or the doses of loop diuretics. ${ }^{59}$

Miller et $\mathrm{al}^{60}$ assessed ambulatory patients with HF in New York Heart Association (NYHA) classes 3 and 4 in terms of death and the need for heart transplantation. Copeptin (cut point $>40 \mathrm{pmol} / \mathrm{L}$; cohort fourth quartile value) and BNP were associated with the primary endpoint, as indicated above. Marked elevations of copeptin concentrations, especially in serial measurements, were independent predictors of poor outcomes. Elevated copeptin, when adjusted for BNP and cardiac troponin T, was an even stronger predictor. These markers appear to reflect the activation of the AVP system, which is present even in the absence of overt clinical changes. It was suggested that a copeptin serial monitoring strategy in combination with hyponatremia may be valuable in identifying patients at a greater risk of HF. Another work by these authors confirmed these reports with a designation of mid-regional proatrial natriuretic peptide. ${ }^{53}$ Tentzeris et $\mathrm{al}^{52}$ estimated the copeptin and high-sensitivity cardiac troponin concentrations in patients with stable chronic HF. Patients were followed up for all-cause mortality and hospitalization due to HF. Their copeptin concentrations showed a moderate but significant correlation inter alia with troponin T $(r=0.40 ; P<0.001)$ and NT-proBNP $(r=0.42 ; P<0.001)$. Copeptin concentrations were significantly higher in patients in the higher NYHA classes $(P=0.002)$. Moreover, elevated copeptin concentrations were significant predictors of the outcome $(P<0.001)$. The combination of both markers showed a graded and highly significant association with an impaired clinical outcome, which proved to be independent of NT-proBNP concentrations (adjusted HR: 1.40; 95\% CI: $1.20-1.70 ; P<0.001)$. Adding copeptin concentrations to a prediction model with NT-proBNP and troponin T resulted in a significant improvement in the performance of the model $(P<0.05)$. A summary of the results of the most important large clinical studies based on copeptin significance in the prognosis of HF are presented in Table 1.
Table I Summary of the results of the most important large clinical studies based on copeptin significance in the prognosis of heart failure

\begin{tabular}{|c|c|c|}
\hline Reference & Population & Conclusions \\
\hline $\begin{array}{l}\text { Stoiser } \\
\text { et a }\left.\right|^{50}\end{array}$ & $n=268$ & $\begin{array}{l}\text { Copeptin was an excellent predictor } \\
\text { of outcome in advanced HF patients. } \\
\text { Its value was superior to that of } \\
\text { BNP in predicting death and a } \\
\text { combined endpoint. }\end{array}$ \\
\hline $\begin{array}{l}\text { Gegenhuber } \\
\text { et } \mathrm{al}^{51}\end{array}$ & $n=137$ & $\begin{array}{l}\text { Copeptin measurements } \\
\text { might have similar predictive } \\
\text { properties compared with BNP } \\
\text { determinations for I-year all-cause } \\
\text { mortality in acute destabilized HF. }\end{array}$ \\
\hline $\begin{array}{l}\text { Tentzeris } \\
\text { et } \mathrm{al}^{52}\end{array}$ & $n=172$ & $\begin{array}{l}\text { Copeptin and hs-cTnT might } \\
\text { predict the clinical outcome of } \\
\text { patients with chronic stable HF. }\end{array}$ \\
\hline Khan et al ${ }^{54}$ & $\mathrm{n}=980$ & $\begin{array}{l}\text { Copeptin may predict adverse } \\
\text { outcomes, especially in those with } \\
\text { elevated NT-proBNP. }\end{array}$ \\
\hline Voors et $\mathrm{al}^{56}$ & $\mathrm{n}=224$ & $\begin{array}{l}\text { Copeptin was a strong and novel } \\
\text { marker for mortality and morbidity } \\
\text { in patients with HF after AMI. }\end{array}$ \\
\hline $\begin{array}{l}\text { Neuhold } \\
\text { et } \mathrm{al}^{62}\end{array}$ & $\mathrm{n}=786$ & $\begin{array}{l}\text { Copeptin was the most potent single } \\
\text { predictor of mortality in patients } \\
\text { with NYHA functional class } 2 \text { and } 3 . \\
\text { Increased levels of copeptin were } \\
\text { linked to excess mortality. }\end{array}$ \\
\hline Maisel et al ${ }^{67}$ & $n=I, 64 \mid$ & $\begin{array}{l}\text { Copeptin was highly prognostic for } \\
90 \text {-day adverse events in patients } \\
\text { with acute HF. }\end{array}$ \\
\hline
\end{tabular}

Abbreviations: $n$, number; HF, heart failure; BNP, brain natriuretic peptide; hs-cTnT, high-sensitivity cardiac troponin T; NT-proBNP, N-terminal prohormone of brain natriuretic peptide; AMI, acute myocardial infarction; NYHA, New York Heart Association.

\section{Copeptin and echocardiography parameters}

Echocardiography plays a key role in the diagnosis of HF. The results together with atypical symptoms, as reported by a patient, often allow for a final diagnosis or for other causes of symptoms to be ruled out. Unfortunately, despite its wide availability, it is not always sufficient for the proper monitoring of the progression of the disease. Hence, there is a need to find a suitable and readily available laboratory marker. There is not enough data on the relationship between the association of echocardiography parameters of impaired cardiac morphology and systolic/diastolic function such as LVEF, left ventricular volumes/diameters, and copeptin serum concentrations.

Kelly et $\mathrm{al}^{55}$ documented that copeptin concentrations were significantly related to the degree of left ventricular dysfunction after myocardial infarction. Copeptin concentrations correlated directly with a wall motion index score (WMIS) and inversely with LVEF at discharge (WMIS, 
$r=0.276, P<0.001$; LVEF, $r=-0.188, P=0.03)$ and follow-up (WMIS, $r=0.244, P<0.001$; LVEF, $r=-0.270, P<0.001$ ). It also correlated with ventricular volumes (left ventricular end systolic volume [LVESV]/diastolic volume [LVEDV]) at follow-up (LVEDV, $r=0.215, P=0.002$; LVESV, $r=0.299$, $P<0.001)$. Copeptin concentrations were associated with ventricular remodeling: deltaEDV (end-diastolic volume) $(r=0.171 ; P=0.015)$ and deltaESV (end-systolic volume) $(r=0.186 ; P=0.008)$. Subjects with increasing LVESV had higher concentrations of copeptin (median $6.30 \mathrm{pmol} / \mathrm{L}$ versus $5.75 \mathrm{pmol} / \mathrm{L} ; P=0.012$ ). A Kaplan-Meier assessment revealed an increased risk in subjects with copeptin $>6.31 \mathrm{pmol} / \mathrm{L}$. Copeptin concentrations in patients after heart transplantation correlated with interventricular septum diameter/thickness $(r=-0.30 ; P<0.01)$ and LVEF $(r=-0.17 ; P<0.05)$. In patients with HF and chronic kidney disease, copeptin concentrations were associated with the dimensions of the left and right ventricles, both atria, and the interventricular septum. ${ }^{61}$ In a group of patients with aortic stenosis with preserved ejection fraction ( $\mathrm{LVEF}>50 \%$ ), copeptin concentrations did not correlate with LVEF, LVEDV, or valvuloarterial impedance, but a positive correlation with left ventricular mass index was observed. There were also no associations with left ventricular diastolic dysfunction in this population. ${ }^{32}$

\section{Copeptin and NYHA class}

As was mentioned in the Introduction, symptoms that are reported by patients are often not typical or are even misinterpreted as being typical of old age or concomitant diseases. However, an appropriate medical history, and echocardiographic and laboratory assessments ensure the correct diagnosis and prognosis of the patient. There are studies that have documented the relationship between copeptin serum concentrations and symptomatology due to the NYHA functional class. ${ }^{62-65}$ Many of these do not only concern the patient's symptoms, but they are also indirectly associated with the symptoms' prognostic significance.

Neuhold et al, ${ }^{62}$ who evaluated patients with HF, showed a significant correlation between the serum copeptin concentration and mortality, which was particularly clearly visible in NYHA classes 2 and 3 (Figure 2). In NYHA functional class 4 , copeptin added additional independent information. In patients in the highest quartile, the levels of copeptin were characterized by a mortality rate of above $50 \%$. It was shown that copeptin was even superior to BNP or NT-proBNP in this study. Silva Marques et $\mathrm{al}^{63}$ assessed the importance of copeptin concentrations depending on the progression of NYHA functional class. Patients with an NYHA functional

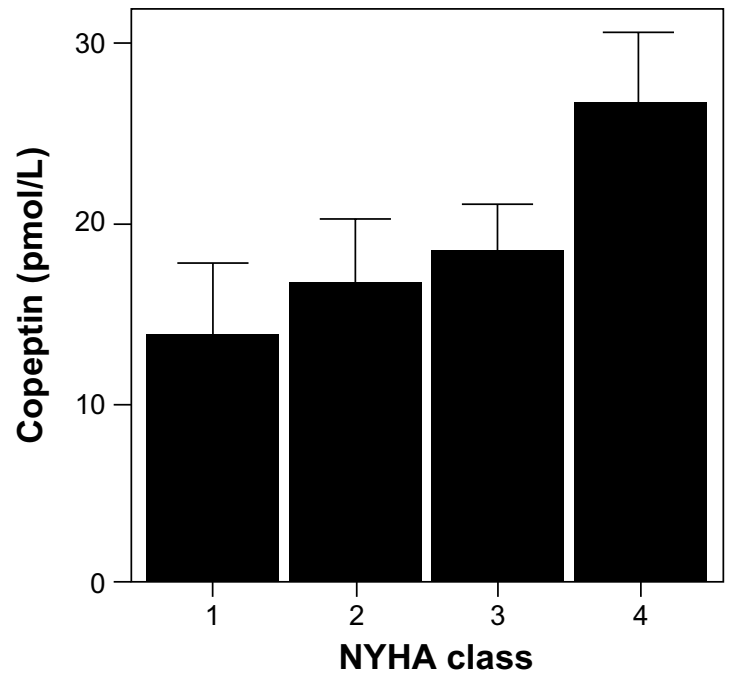

Figure 2 Copeptin concentrations and NYHA class.

Note: Reprinted with permission from the Journal of the American College of Cardiology, Vol 52, Neuhold S, Huelsmann M, Strunk G, et al, Comparison of copeptin, B-type natriuretic peptide, and amino-terminal pro-B-type natriuretic peptide in patients with chronic heart failure: prediction of death at different stages of the disease, 266-272. Copyright Elsevier (C) 2008.62

Abbreviation: NYHA, New York Heart Association.

class $>2$ were characterized by higher concentrations of copeptin (area under the curve [AUC]: $0.76 ; P<0.01$ ) and NT-proBNP (AUC: $0.81 ; P<0.01$ ), and these proteins were characterized by a high level of sensitivity and specificity in predicting the NYHA class.

In addition to copeptin levels, echocardiographic parameters such as pulmonary artery systolic pressure and inferior vena cava inspiratory diameter showed the best performance for the diagnosis of functional class $>2$ in patients with LVEF $<40 \%$. The association of copeptin concentrations with NYHA class was observed in the previously mentioned study by Tentzeris et al. ${ }^{52}$ In a population of patients following heart transplantation, copeptin concentrations were significantly associated with NYHA class and renal function. ${ }^{64,65}$ The copeptin concentration was significantly lower among kidney allograft patients than among orthotopic heart recipients $(0.71 \pm 0.13 \mathrm{ng} / \mathrm{mL}$ versus $0.99 \pm 0.36 \mathrm{ng} / \mathrm{mL}$; $P<0.001)$. The copeptin concentration was higher in chronic kidney disease stage 4 than in stage 2 , and similarly in NYHA class 3 versus class 1 . The copeptin concentration correlated with the following parameters of kidney function: creatinine ( $r=0.39 ; P<0.001$ ); estimated GFR by Modification of Diet in Renal Disease ( $r=-0.24 ; P<0.01)$; estimated GFR by Chronic Kidney Disease Epidemiology Collaboration ( $r=-0.25 ; P<0.01)$; creatinine clearance by Cockcroft-Gault ( $r=-0.27 ; P<0.01)$; 24-hour creatinine clearance $(r=-0.21$; $P<0.05)$; and high-density lipoproteins $(r=0.18 ; P<0.05)$. Associations with BNP $(r=0.25 ; P<0.01)$, interventricular 
septum diameter/thickness $(r=-0.30 ; P<0.01)$, and LVEF $(r=-0.17 ; P<0.05)$ were also observed. The authors suggested that it also might predict the outcomes of orthotopic heart transplant patients.

Correlations between copeptin concentrations and NYHA functional class were also documented in patients with HF and chronic kidney disease. ${ }^{61}$ The creation of an arteriovenous fistula in these patients might contribute to the development or worsening of congestive HF. Higher copeptin concentrations were observed in older proximal fistula hemodialysis patients with anemia and acidosis. There were also associations with significant changes in all of the intracardiac dimensions, including the right ventricle, both atria, and the interventricular, septum as well as an increase in the end-systolic and end-diastolic left ventricular dimensions. In a multiple logistic regression analysis, the only associate of copeptin concentrations was the NYHA functional class. Copeptin concentrations in hemodialysis patients depended on cardiac function, and they may be associated with the pathogenesis of cardiac disease in these patients.

\section{Copeptin and acute dyspnea}

Patients who cause considerable diagnostic problems in an emergency department (ED) are those who are suffering from shortness of breath of an unknown origin. Even a set of laboratory tests and imaging, including echocardiography and chest X-rays, do not make diagnosing these patients easy. Perhaps in the future, the additional evaluation of copeptin concentrations may help in the differential algorithm.

Interesting data come from the $\mathrm{BACH}$ study (the Biomarkers in Acute Heart Failure study), ${ }^{66,67}$ which was a prospective, international trial of patients who came to the ED with nontraumatic dyspnea. The study included 1,641 patients. The AUC for the 14-day mortality receiver operating characteristic curve was 0.803 for copeptin. In a different combination, mid-regional pro-adrenomedullin (MR-proADM) and copeptin had the best 14-day mortality prediction (AUC $=0.818$ ) versus all of the other markers (NT-proBNP, BNP, troponin). The authors concluded that MR-proADM and copeptin, alone or in combination, may provide superior short-term mortality prediction. This study also showed a significantly higher 90-day mortality rate, readmission rate, and emergency department visit rate in patients with elevated copeptin concentrations, especially in patients with hyponatremia $(P<0.01)$. In another study of patients presenting to the ED with dyspnea, ${ }^{68}$ the copeptin concentration was also confirmed as a promising new prognostic marker for short-term mortality (Figure 3). Copeptin concentrations were elevated in non-survivors $(n=29)$ compared to survivors at 30 days $(108 \mathrm{pmol} / \mathrm{L}$; interquartile

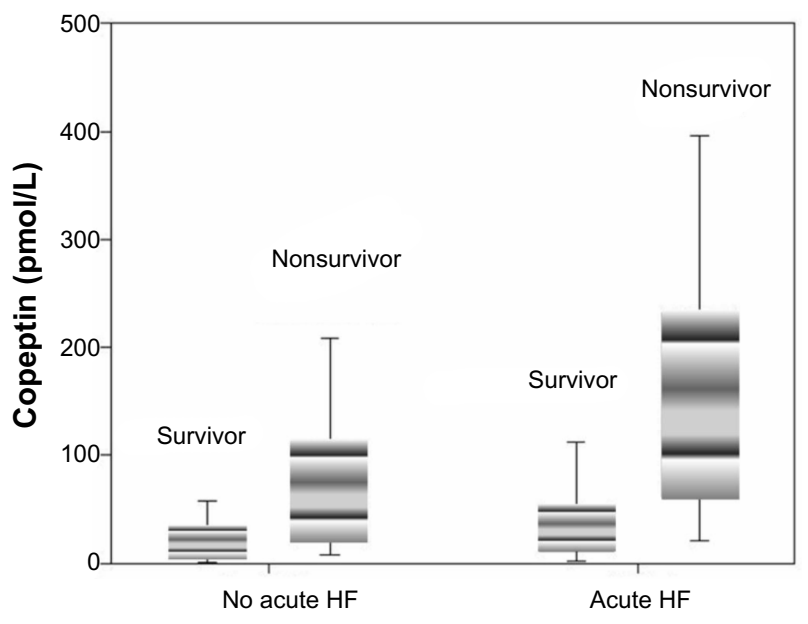

Figure 3 Copeptin concentrations and survival of patients with/without acute HF. Note: Adapted from Potocki M, Breidthardt T, Mueller A, et al. Copeptin and risk stratification in patients with acute dyspnea. Crit Care. 2010;14(6):R213.68 Abbreviation: HF, heart failure.

range: $37-197 \mathrm{pmol} / \mathrm{L}$ versus $18 \mathrm{pmol} / \mathrm{L}$; interquartile range: 7-43 pmol/L; $P<0.0001)$. Copeptin concentrations were the strongest independent predictor for short-term mortality in all patients (HR: 3.88 [1.94-7.77]; $P<0.001$ ) and especially in patients with acute decompensated HF (HR: 5.99 [2.55-14.07]; $P<0.0001)$. However, not all data are clear. Dieplinger et $\mathrm{al}^{69}$ showed that BNP and mid-regional proatrial natriuretic peptide (MR-proANP) were the only independent diagnostic markers of HF in patients presenting to the ED with dyspnea. Although median plasma concentrations of copeptin and other biomarkers were higher in patients with dyspnea that was attributable to acute destabilized HF than in patients with dyspnea that was attributable to other reasons, multivariate logistic regression analysis pointed only to the importance of increased BNP and MR-proANP.

One of the main symptoms of acute HF or the exacerbation of chronic HF is the increase in edema of the lower limbs. Breidthardt et $\mathrm{al}^{70}$ evaluated patients coming to the ED because of HF symptoms. Although the duration of dyspnea preceding the ED visit was longer in patients with more extensive edema, the activity of the AVP system did not seem to be a key determinant of the presence or extent of lower extremity edema in acute HF. Copeptin concentrations above $40.11 \mathrm{pmol} / \mathrm{L}$ had a high specificity for the diagnosis of acute respiratory distress syndrome/acute lung injury in patients presenting with cardiogenic pulmonary edema. In comparison to NT-proBNP, copeptin concentration was an even stronger prognostic marker for short-term mortality. ${ }^{71}$

\section{Copeptin and pharmacotherapy}

Interesting data has come out of the work related to the effect of pharmacotherapy of HF on the concentration 
of copeptin. One of these was an assessment of the impact of a $\beta$-adrenergic blocker in patients with HF with reduced LVEF or preserved LVEF. ${ }^{72}$ A continuous decreasing trend of copeptin concentrations in HF patients with reduced LVEF was observed during up-titration (at 12 weeks; $P=0.026$ ). In contrast to copeptin concentrations, the results came out in favor of NT-proBNP in HF patients with preserved LVEF. Miller et $\mathrm{al}^{73}$ evaluated the prognostic and therapy-monitoring potential of copeptin concentrations in patients with decompensated HF. All of the patients received nesiritide, a recombinant form of the 32-amino acid human B-type natriuretic peptide, which was initially considered to be beneficial for acute decompensated congestive HF. Copeptin concentrations that were elevated at baseline prior to the nesiritide infusion demonstrated significant acute reductions in plasma levels in response to the therapy. Copeptin concentrations were higher in posthospital nonsurvivors, and with the proportional hazards model, were associated with an increased mortality risk $(P=0.04)$. The concentrations of copeptin contributed significantly to risk stratification in this group of patients with no additive effect of the BNP measurement. Development of HF risk stratification after myocardial infarction by copeptin concentrations seems to be crucial and may be important in the future in terms of the use of AVP receptor antagonists such as vaptans. ${ }^{74,75}$

\section{Copeptin in elderly}

$\mathrm{HF}$ is a disease which, in spite of the progress of medicine, will affect more of the elderly population. This group of patients is burdened with a number of comorbidities that hinder the clinical interpretation. Hence, finding the specific marker that will determine prognosis is extremely important. Therefore, the association between the plasma concentrations of copeptin was evaluated together with the concentrations of NT-proBNP and mortality in elderly patients with symptoms of $\mathrm{HF}^{76}$ A total of 470 patients with $\mathrm{HF}$ symptoms were enrolled in the study. After a median follow-up of 13 years, there were 226 deaths from all causes, including 146 deaths from cardiovascular causes. An increased concentration of copeptin was associated with an increased risk of all-cause mortality (fourth quartile versus first quartile: $69.5 \%$ versus $38.5 \%$, respectively; HR: 2.04; 95\% CI: 1.38-3.02) and cardiovascular mortality (fourth quartile versus first quartile: 46.6\% versus 26.5\%; HR: 1.94; 95\% CI: $1.20-3.13)$. The combination of elevated NT-proBNP concentrations and elevated copeptin concentrations was also associated with an increased risk of all-cause mortality (copeptin fourth quartile: HR: 1.63; 95\% CI: 1.08-2.47; $P=0.01$; NT-proBNP fourth quartile: HR: 3.17; 95\% CI: 2.02-4.98; $P<0.001)$. However, not all data support this relationship. In a recently published study, Wannamethee et $\mathrm{al}^{77}$ examined the use of copeptin and NT-proBNP concentrations in improving the risk prediction and stratification of $\mathrm{HF}$ in older men with and without cardiovascular disease. A total of 3,870 men aged 60-79 years with no diagnosed HF were followed up for a mean period of 11 years, during which there were $254 \mathrm{HF}$ cases. In contrast to NT-proBNP concentrations, copeptin concentrations were associated with HF only in men with cardiovascular disease (myocardial infarction, angina, or stroke) and they did not improve the prediction of HF after the inclusion of conventional risk factors such as age, obesity, diabetes, hypertension, history of myocardial infarction, and angina $(P=0.95)$. The assessment of the differential diagnostic performance and acceptability of a range of copeptin against a clinical diagnosis using portable echocardiography was also performed. A total of 405 residents, aged 65-100 years in long-term care facilities, were enrolled into the study. Novel biomarkers copeptin, MR-proADM, and MR-proANP, and common signs and symptoms had little diagnostic utility. ${ }^{78}$

Despite the fact that the data presented here are not consistent, copeptin concentrations may be an important conditional marker for further prognosis in acute and chronic HF that is primarily associated with left ventricular dysfunction, regardless of age. This still requires further confirmation.

\section{Discussion}

Studies, which are quoted in this review, often show controversial results of the importance of copeptin in different clinical settings. However, most of the studies are favorable and promising. Copeptin serum concentration was independently related to mortality in each symptomatic stage of $\mathrm{HF}$, especially in NYHA functional classes 2 and $3 .{ }^{62}$ This is an important finding because these intermediate classes are more difficult to resolve in the ambulatory setting than are the more obvious NYHA functional classes 1 and $4 .^{62}$ For patients in the most severe stage of HF, copeptin provided independent additional information, but it was inferior to sodium levels and, especially, to GFR. In this study, BNP provided no additional information. It can be presumed that in the case of end-stage HF, fluid-regulating hormones might be of limited value for prognosis because kidney function as the morphologic substrate of fluid regulation becomes paramount. ${ }^{62}$ Maybe one marker could not be sufficient to provide the full prognostic information of the fluid-regulating system in HF. ${ }^{62}$ Copeptin could, therefore, emerge as an independent marker to identify HF patients from the whole 
spectrum of the disease, who could benefit from adjunct therapy with vaptans. This could, in the future, permit a more adjusted therapy for these patients. Moreover, copeptin is a new promising prognostic marker for short-term mortality, which is an independent additive to natriuretic peptide levels in patients with acute dyspnea. ${ }^{68}$ Additional advantages of copeptin assessment were confirmed in another study. ${ }^{79}$ It was revealed that patients at low estimated risk according to plasma NT-proBNP levels were at significantly higher risk for worse outcomes with higher copeptin levels. The results of this study suggest that the preoperative determination of this new biomarker could substantially improve the prediction of perioperative and postoperative outcomes in vascular surgery patients. ${ }^{79}$

Things to check are the interdependences between sodium balance and copeptin concentration. It was previously mentioned that copeptin concentrations did not predict future development of hyponatremia, and copeptin was a predictor of mortality in HF regardless of the serum sodium concentrations. ${ }^{59}$ It was suggested that a serial monitoring strategy of copeptin in combination with hyponatremia can be valuable in identifying patients at higher risk of $\mathrm{HF}^{60}$ Copeptin concentrations in the hyponatremic population were higher in patients with a hypervolemic volume state and in patients with HF and renal failure. ${ }^{80}$

It is important to assess the relationship between serum concentrations of copeptin and NT-proBNP. Interesting data come from the Christensen et al study ${ }^{81}$ It is well known low body mass index (BMI) is associated with a poor outcome in chronic HF. ${ }^{81}$ An inverse association between BMI and NTproBNP has been reported, but BMI did not correlate with copeptin concentrations. Perhaps in this group of patients even with normal NT-proBNP, copeptin will play a prognostic role in the future; this requires further study.

Interesting data come from a survey of patients with HF symptoms due to aortic stenosis with preserved LVEF. ${ }^{32}$ Although both markers grew along with the progression of the disease, there was no correlation between serum concentrations of copeptin and NT-proBNP. It seems, therefore, that the two biomarkers may reflect the potentially different pathomechanisms of the disease. The results of basic research support this hypothesis. NT-proBNP reflects myocardial congestion, and produced in the central nervous system is copeptin, which provides information about neurohumoral disorders. The pathogenesis of its actions in patients with aortic stenosis is as follows: on the one hand, an excessive level of activity of the AVP promotes remodeling and progression of valvular disease; on the other hand, stress (which is involved in the development of stenosis) promotes the release of copeptin..$^{32}$ Measuring the concentration of copeptin, next to the concentration of NT-proBNP, clinical evaluation and transthoracic echocardiographic parameters can complement diagnostic tests in patients with aortic stenosis in order to determine the severity of the disease and the selection of the appropriate time for surgical treatment. ${ }^{32}$

Interesting observations for the determination of NTproBNP and copeptin in the elderly were showed in the CIBIS-ELD Study (Cardiac Insufficiency Bisoprolol Study in Elderly). ${ }^{72}$ During the $\beta$-blocker therapy in a population of patients with HF and impaired LVEF, copeptin concentrations decreased faster than did NT-proBNP concentrations. Reverse dependencies were observed in patients with HF and preserved LVEF, which first occurred to normalize the concentration of NT-proBNP. These results may have important implications in the interpretation of elevated concentrations of both markers in HF.

Although many stressors are involved in the release of copeptin, in the situations described above, the designation of copeptin can serve as an additional assessment of the patient's prognosis. As mentioned in the Copeptin in cardiovascular and kidney diseases section the prognostic value of copeptin was noted for different acute illnesses. This reflects the severity of the disorder and can be used to identify high-risk patients. Due to the multifunctional potential of copeptin, the results must be interpreted in a clinical setting. When used in combination, with routine markers, copeptin provides more detailed diagnostic information, especially when used in cardiovascular diseases. This information helps in prognosis assessment, it may affect the introduction and subsequent monitoring of therapy, and it enables the provision of individualized and optimal patient care. Additionally, the introduction of copeptin into clinical practice can provide benefits on a larger scale, proposing changes in the allocation of financial resources within the health care system. Further large, randomized trials are needed to evaluate the clinical benefits in the everyday use of copeptin in practice and patient care. The costs of the routine measurements of copeptin and the lack of sufficient clinical data argue against the introduction of copeptin to diagnose myocardial ischemia. ${ }^{14}$ Widespread use of panel ischemia (copeptin and troponin) could potentially reduce the costs generated during long-term monitoring. The patient requires frequent blood sampling in cases of emergency, or is burdened with unnecessary hospitalization. This is due to the uncertainty of the first diagnostic test. This seems especially important in acute coronary syndromes, where appropriate diagnosis of the 
patient who presents to the ED with chest pain seems to be the most important in terms of further invasive treatment. ${ }^{14}$ This is probably also important in HF, the main complication of myocardial infarction, both in clinical and financial terms, but requires further analysis.

\section{Conclusion}

Copeptin constitutes a novel marker in cardiovascular diseases. HF, both acute and chronic, is one of the areas of interest in which the role of the copeptin concentration is particularly important. A contemporary assessment of clinical signs supplemented with serum copeptin concentrations may help in the diagnosis and risk evaluation of HF. The many clinical settings in which elevated copeptin concentrations were observed require careful consideration and further research in order to strengthen the position of copeptin concentrations in daily practice.

\section{Disclosure}

The authors report no conflicts of interest in this work.

\section{References}

1. Oudejans I, Mosterd A, Bloemen JA, et al. Clinical evaluation of geriatric outpatients with suspected heart failure: value of symptoms, signs, and additional tests. Eur J Heart Fail. 2011;13(5):518-527.

2. Fonseca C. Diagnosis of heart failure in primary care. Heart Fail Rev. 2006;11(2):95-107.

3. Mosterd A, Hoes AW. Clinical epidemiology of heart failure. Heart. 2007;93(9):1137-1146.

4. Stewart S, MacIntyre K, Hole DJ, Capewell S, McMurray JJ. More 'malignant' than cancer? Five-year survival following a first admission for heart failure. Eur J Heart Fail. 2001;3(3):315-322.

5. Stewart S, Ekman I, Ekman T, Odén A, Rosengren A. Population impact of heart failure and the most common forms of cancer: a study of 1162 309 hospital cases in Sweden (1988 to 2004). Circ Cardiovasc Qual Outcomes. 2010;3(6):573-580.

6. Jhund PS, Macintyre K, Simpson CR, et al. Long-term trends in first hospitalization for heart failure and subsequent survival between 1986 and 2003: a population study of 5.1 million people. Circulation. 2009;119(4):515-523.

7. McMurray JJ, Adamopoulos S, Anker SD, et al. ESC Committee for Practice Guidelines. ESC Guidelines for the diagnosis and treatment of acute and chronic heart failure 2012: The Task Force for the Diagnosis and Treatment of Acute and Chronic Heart Failure 2012 of the European Society of Cardiology. Developed in collaboration with the Heart Failure Association (HFA) of the ESC. Eur Heart J. 2012;33(14): 1787-1847.

8. Robertson GL, Mahr EA, Athar S, Sinha T. Development and clinical application of a new method for the radioimmunoassay of arginine vasopressin in human plasma. J Clin Invest. 1973;52(9):2340-2352.

9. Holwerda DA. A glycopeptide from the posterior lobe of pig pituitaries. I. Isolation and characterization. Eur J Biochem. 1972;28(3):334-339.

10. Morgenthaler NG, Struck J, Alonso C, Bergmann A. Assay for the measurement of copeptin, a stable peptide derived from the precursor of vasopressin. Clin Chem. 2006;52(1):112-119.

11. Kasting NW, Mazurek MF, Martin JB. Endotoxin increases vasopressin release independently of known physiological stimuli. Am J Physiol. 1985;248(4 Pt 1):E420-E424.
12. Passeron A, Dupeux S, Blanchard A. [Hyponatremia: from physiopathology to practice]. Rev Med Interne. 2010;31(4):277-286. French.

13. Thibonnier M, Marchetti J, Corvol P, Menard J, Milliez P. Abnormal regulation of antidiuretic hormone in idiopathic edema. Am J Med. 1979;67(1):67-73.

14. Morawiec B, Kawecki D. Copeptin: a new marker in cardiology. J Cardiovasc Med (Hagerstown). 2013;14(1):19-25.

15. Morgenthaler NG. Copeptin: A biomarker of cardiovascular and renal function. Congest Heart Fail. 2010;16 Suppl 1:37-44.

16. Rivier $\mathrm{C}$, Vale W. Interaction of corticotrophin-releasing factor and arginine vasopressin on adrenocorticotropin secretion in vivo. Endocrinology. 1983;113(3):939-942.

17. Milsom SR, Conaglen JV, Donald RA, Espiner EA, Nicholls MG, Livesey JH. Augmentation of the response to CRF in man: relative contributions of endogenous angiotensin and vasopressin. Clin Endocrinol (Oxf). 1985;22(5):623-629.

18. Holmes CL, Landry DW, Granton JT. Science review: vasopressin and the cardiovascular system part 2 - clinical physiology. Crit Care. 2004;8(1):15-23.

19. Thibonnier M, Conarty DM, Preston JA, Plesnicher CL, Dweik RA, Erzurum SC. Human vascular endothelial cells express oxytocin receptors. Endocrinology. 1999;140(3):1301-1309.

20. Gutkowska J, Jankowski M, Lambert C, Mukaddam-Daher S, Zingg HH, McCann SM. Oxytocin releases atrial natriuretic peptide by combining with oxytocin receptors in the heart. Proc Natl Acad Sci U S A. 1997;94(21):11704-11709.

21. Zenteno-Savin T, Sada-Ovalle I, Ceballos G, Rubio R. Effects of arginine vasopressin in the heart are mediated by specific intravascular endothelial receptors. Eur J Pharmacol. 2000;410(1):15-23.

22. Fenske W, Störk S, Blechschmidt A, Maier SG, Morgenthaler NG, Allolio B. Copeptin in the differential diagnosis of hyponatremia. $J$ Clin Endocrinol Metab. 2009;94(1):123-129.

23. Katan M, Morgenthaler NG, Dixit KC, et al. Anterior and posterior pituitary function testing with simultaneous insulin tolerance test and a novel copeptin assay. J Clin Endocrinol Metab. 2007;92(7):2640-2643.

24. Uscn Life Science Inc. [homepage on the Internet]. Available from: http://www.uscnk.com/directory/Copeptin(CPP)-0365.htm. Accessed May 6, 2014.

25. von Haehling S, Papassotiriou J, Morgenthaler NG, et al. Copeptin as a prognostic factor for major adverse cardiovascular events in patients with coronary artery disease. Int J Cardiol. 2012;162(1):27-32.

26. Folli C, Consonni D, Spessot M, et al. Diagnostic role of copeptin in patients presenting with chest pain in the emergency room. Eur J Intern Med. 2013;24(2):189-193.

27. Dupuy AM, Chastang E, Cristol JP, Jreige R, Lefebvre S, Sebbane M. Analytical performances of the newly developed, fully automated Kryptor Copeptin assay: which impact factor for myocardial infarction rules out in the emergency department? Clin Lab. 2012;58(7-8):635-644.

28. Charpentier S, Maupas-Schwalm F, Cournot M, Elbaz M, Botella JM, Lauque D. Combination of copeptin and troponin assays to rapidly rule out non-ST elevation myocardial infarction in the emergency department. Acad Emerg Med. 2012;19(5):517-524.

29. Ray P, Charpentier S, Chenevier-Gobeaux C, et al. Combined copeptin and troponin to rule out myocardial infarction in patients with chest pain and a history of coronary artery disease. Am J Emerg Med. 2012;30(3): 440-448.

30. Lotze U, Lemm H, Heyer A, Müller K. Combined determination of highly sensitive troponin $\mathrm{T}$ and copeptin for early exclusion of acute myocardial infarction: first experience in an emergency department of a general hospital. Vasc Health Risk Manag. 2011;7:509-515.

31. Günebakmaz O, Celik A, Inanc MT, et al. Copeptin level and copeptin response to percutaneous balloon mitral valvuloplasty in mitral stenosis. Cardiology. 2011;120(4):221-226.

32. Mizia-Stec K, Lasota B, Mizia M, et al. Copeptin constitutes a novel biomarker of degenerative aortic stenosis. Heart Vessels. 2013;28(5): 613-619. 
33. Lindner KH, Strohmenger HU, Ensinger H, Hetzel WD, Ahnefeld FW, Georgieff M. Stress hormone response during and after cardiopulmonary resuscitation. Anesthesiology. 1992;77(4):662-668.

34. Dünser MW, Mayr AJ, Ulmer H, et al. Arginine vasopressin in advanced vasodilatory shock: a prospective, randomized, controlled study. Circulation. 2003;107(18):2313-2319.

35. Stolz D, Christ-Crain M, Morgenthaler NG, et al. Copeptin, C-reactive protein, and procalcitonin as prognostic biomarkers in acute exacerbation of COPD. Chest. 2007;131(4):1058-1067.

36. Fenske W, Quinkler M, Lorenz D, et al. Copeptin in the differential diagnosis of the polydipsia-polyuria syndrome - revisiting the direct and indirect water deprivation tests. J Clin Endocrinol Metab. 2011;96(5): 1506-1515.

37. Müller B, Morgenthaler N, Stolz D, et al. Circulating levels of copeptin, a novel biomarker, in lower respiratory tract infections. Eur $J$ Clin Invest. 2007;37(2):145-152.

38. Morgenthaler NG, Müller B, Struck J, Bergmann A, Redl H, Christ-Crain M. Copeptin, a stable peptide of the arginine vasopressin precursor, is elevated in hemorrhagic and septic shock. Shock. 2007;28(2):219-226.

39. Katan M, Fluri F, Morgenthaler NG, et al. Copeptin: a novel, independent prognostic marker in patients with ischemic stroke. Ann Neurol. 2009;66(6):799-808

40. Zweifel C, Katan M, Schuetz P, et al. Copeptin is associated with mortality and outcome in patients with acute intracerebral hemorrhage. BMC Neurol. 2010,10:34.

41. Dong XQ, Huang M, Yang SB, Yu WH, Zhang ZY. Copeptin is associated with mortality in patients with traumatic brain injury J Trauma. 2011;71(5):1194-1198.

42. Fenske W, Wanner C, Allolio B, et al. German Diabetes, Dialysis Study Investigators. Copeptin levels associate with cardiovascular events in patients with ESRD and type 2 diabetes mellitus. J Am Soc Nephrol. 2011;22(4):782-790.

43. Bankir L, Bouby N, Ritz E. Vasopressin: a novel target for the prevention and retardation of kidney disease? Nat Rev Nephrol. 2013;9(4):223-239.

44. Li X, Yang XC, Sun QM, Chen XD, Li YC. Brain natriuretic peptide and copeptin levels are associated with cardiovascular disease in patients with chronic kidney disease. Chin Med J (Engl). 2013;126(5): 823-827.

45. Velho G, Bouby N, Hadjadj S, et al. Plasma copeptin and renal outcomes in patients with type 2 diabetes and albuminuria. Diabetes Care. 2013;36(11):3639-3645.

46. Bosselmann H, Egstrup M, Rossing K, et al. Prognostic significance of cardiovascular biomarkers and renal dysfunction in outpatients with systolic heart failure: A long term follow-up study. Int J Cardiol. 2013;170(2):202-207.

47. Fukuzawa J, Haneda T, Kikuchi K. Arginine vasopressin increases the rate of protein synthesis in isolated perfused adult rat heart via the $\mathrm{V} 1$ receptor. Mol Cell Biochem. 1999;195(1-2):93-98.

48. Goldsmith SR. Vasopressin as vasopressor. Am J Med. 1987;82(6): 1213-1219.

49. Fan YH, Zhao LY, Zheng QS, Dong H, Wang HC, Yang XD. Arginine vasopressin increases iNOS-NO system activity in cardiac fibroblasts through NF-kappaB activation and its relation with myocardial fibrosis. Life Sci. 2007;81(4):327-335.

50. Stoiser B, Mörtl D, Hülsmann M, et al. Copeptin, a fragment of the vasopressin precursor, as a novel predictor of outcome in heart failure. Eur J Clin Invest. 2006;36(11):771-778.

51. Gegenhuber A, Struck J, Dieplinger B, et al. Comparative evaluation of B-type natriuretic peptide, mid-regional pro-A-type natriuretic peptide, mid-regional pro-adrenomedullin, and Copeptin to predict 1-year mortality in patients with acute destabilized heart failure. $J$ Card Fail. 2007;13(1):42-49.

52. Tentzeris I, Jarai R, Farhan S, et al. Complementary role of copeptin and high-sensitivity troponin in predicting outcome in patients with stable chronic heart failure. Eur J Heart Fail. 2011;13(7):726-733.
53. Miller WL, Hartman KA, Grill DE, Struck J, Bergmann A, Jaffe AS. Serial measurements of midregion proANP and copeptin in ambulatory patients with heart failure: incremental prognostic value of novel biomarkers in heart failure. Heart. 2012;98(5):389-394.

54. Khan SQ, Dhillon OS, O'Brien RJ, et al. C-terminal provasopres$\sin$ (copeptin) as a novel and prognostic marker in acute myocardial infarction: Leicester Acute Myocardial Infarction Peptide (LAMP) study. Circulation. 2007;115(16):2103-2110.

55. Kelly D, Squire IB, Khan SQ, et al. C-terminal provasopressin (copeptin) is associated with left ventricular dysfunction, remodeling, and clinical heart failure in survivors of myocardial infarction. $J$ Card Fail. 2008;14(9):739-745.

56. Voors AA, von Haehling S, Anker SD, et al. OPTIMAAL Investigators. $\mathrm{C}$-terminal provasopressin (copeptin) is a strong prognostic marker in patients with heart failure after an acute myocardial infarction: results from the OPTIMAAL study. Eur Heart J. 2009;30(10):1187-1194.

57. Neuhold S, Huelsmann M, Strunk G, et al. Prognostic value of emerging neurohormones in chronic heart failure during optimization of heart failure-specific therapy. Clin Chem. 2010;56(1):121-126.

58. Masson S, Latini R, Carbonieri E, et al. GISSI-HF Investigators. The predictive value of stable precursor fragments of vasoactive peptides in patients with chronic heart failure: data from the GISSI-heart failure (GISSI-HF) trial. Eur J Heart Fail. 2010;12(4):338-347.

59. Balling L, Kistorp C, Schou M, et al. Plasma copeptin levels and prediction of outcome in heart failure outpatients: relation to hyponatremia and loop diuretic doses. J Card Fail. 2012;18(5):351-358.

60. Miller WL, Grill DE, Struck J, Jaffe AS. Association of hyponatremia and elevated copeptin with death and need for transplantation in ambulatory patients with chronic heart failure. Am J Cardiol. 2013;111(6): 880-885.

61. Malyszko J, Levin-Iaina N, Malyszko JS, Kozminski P, Koc-Zorawska E, Mysliwiec M. Copeptin and its relation to arteriovenous fistula (AVF) type and NYHA class in hemodialysis patients. Ren Fail. 2011;33(10): 929-934.

62. Neuhold S, Huelsmann M, Strunk G, et al. Comparison of copeptin, B-type natriuretic peptide, and amino-terminal pro-B-type natriuretic peptide in patients with chronic heart failure: prediction of death at different stages of the disease. J Am Coll Cardiol. 2008;52(4):266-272.

63. Silva Marques J, Luz-Rodrigues H, David C, G Almeida A, Nunes Diogo A. [Biomarkers of functional class in systolic heart failure: the relevance of copeptin]. Rev Port Cardiol. 2012;31(11):701-710. Portuguese.

64. Przybylowski P, Malyszko J, Malyszko JS. Copeptin in heart transplant recipients depends on kidney function and intraventricular septal thickness. Transplant Proc. 2010;42(5):1808-1811.

65. Malyszko J, Przybylowski P, Koc-Zorawska E, et al. Copeptin in relation to New York Heart Association class in heart transplant recipients and kidney transplant recipients. Transplant Proc. 2010;42(10): 4259-4262.

66. Peacock WF, Nowak R, Christenson R, et al. Short-term mortality risk in emergency department acute heart failure. Acad Emerg Med. 2011;18(9):947-958.

67. Maisel A, Xue Y, Shah K, et al. Increased 90-day mortality in patients with acute heart failure with elevated copeptin: secondary results from the Biomarkers in Acute Heart Failure (BACH) study. Circ Heart Fail. 2011;4(5):613-620.

68. Potocki M, Breidthardt T, Mueller A, et al. Copeptin and risk stratification in patients with acute dyspnea. Crit Care. 2010;14(6):R213.

69. Dieplinger B, Gegenhuber A, Haltmayer M, Mueller T. Evaluation of novel biomarkers for the diagnosis of acute destabilised heart failure in patients with shortness of breath. Heart. 2009;95(18):1508-1513.

70. Breidthardt T, Irfan A, Klima T, et al. Pathophysiology of lower extremity edema in acute heart failure revisited. Am J Med. 2012; 125(11):1124.e1-1124.e8.

71. Lin Q, Fu F, Chen H, Zhu B. Copeptin in the assessment of acute lung injury and cardiogenic pulmonary edema. Respir Med. 2012;106(9): $1268-1277$. 
72. Loncar G, von Haehling S, Tahirovic E, et al. Effect of beta blockade on natriuretic peptides and copeptin in elderly patients with heart failure and preserved or reduced ejection fraction: results from the CIBIS-ELD trial. Clin Biochem. 2012;45(1-2):117-122.

73. Miller WL, Hartman KA, Hodge DO, et al. Response of novel biomarkers to BNP infusion in patients with decompensated heart failure: a multimarker paradigm. J Cardiovasc Transl Res. 2009;2(4):526-535.

74. Konstam MA, Gheorghiade M, Burnett JC, et al. Efficacy of Vasopressin Antagonism in Heart Failure Outcome Study With Tolvaptan (EVEREST) Investigators. Effects of oral tolvaptan in patients hospitalized for worsening heart failure: the EVEREST Outcome Trial. JAMA. 2007;297(12):1319-1331.

75. Gheorghiade M, Konstam MA, Burnett JC, et al. Efficacy of Vasopressin Antagonism in Heart Failure Outcome Study With Tolvaptan (EVEREST) Investigators. Short-term clinical effects of tolvaptan, an oral vasopressin antagonist, in patients hospitalized for heart failure: the EVEREST Clinical Status Trials. JAMA. 2007;297(12):1332-1343.

76. Alehagen U, Dahlström U, Rehfeld JF, Goetze JP. Association of copeptin and N-terminal proBNP concentrations with risk of cardiovascular death in older patients with symptoms of heart failure. JAMA. 2011;305(20):2088-2095.
77. Wannamethee SG, Welsh P, Whincup PH, Lennon L, Papacosta O, Sattar N. $\mathrm{N}$-terminal pro brain natriuretic peptide but not copeptin improves prediction of heart failure over other routine clinical risk parameters in older men with and without cardiovascular disease: population-based study. Eur J Heart Fail. 2014;16(1):25-32.

78. Mason JM, Hancock HC, Close H, et al. Utility of biomarkers in the differential diagnosis of heart failure in older people: findings from the heart failure in care homes $(\mathrm{HFinCH})$ diagnostic accuracy study. PLoS One. 2013;8(1):e53560.

79. Jarai R, Mahla E, Perkmann T, et al. Usefulness of pre-operative copeptin concentrations to predict post-operative outcome after major vascular surgery. Am J Cardiol. 2011;108(8):1188-1195.

80. Nigro N, Müller B, Morgenthaler N, et al. The use of copeptin, the stable peptide of the vasopressin precursor, in the differential diagnosis of sodium imbalance in patients with acute diseases. Swiss Med Wkly. 2011;141:w13270.

81. Christensen HM, Schou M, Goetze JP, et al. Body mass index in chronic heart failure: association with biomarkers of neurohormonal activation, inflammation and endothelial dysfunction. BMC Cardiovasc Disord. 2013;13:80.

\section{Dovepress}

\section{Publish your work in this journal}

Research Reports in Clinical Cardiology is an international, peerreviewed, open access journal publishing original research, reports, editorials, reviews and commentaries on all areas of cardiology in the clinic and laboratory. The manuscript management system is completely online and includes a very quick and fair peer-review system.

Submit your manuscript here: http://www.dovepress.com/research-reports-in-clinical-cardiology-journal
Visit http://www.dovepress.com/testimonials.php to read real quotes from published authors. 